7. Майкл, Ласло Вычислительная геометрия и компьютерная графика на C++ [Текст] / Ласло Майкл; пер. с англ. М.: «Издательство «БИНОМ», 1997. - 340 с.

8. Мухачева, Э. А. Рациональный раскрой прямоугольных листов на прямоугольные заготовки [Текст] / Э. А. Мухачева // Оптимальное планирование. - 1966. - Вып. 6. C. $39-41$.

9. Тот, Л. Ф. Расположение на плоскости, в сфере и пространстве [Текст] / Л. Ф. Тот; пер. с англ. - М.:Физматгиз, 1958. - 132 c.

10. Чупринка, В. И. Алгоритм построения опорной функции ля плоских геометрических объектов [Текст] : межд. сб. науч. тр. / В. И. Чупринка, В. С. Мурженко, П. В. Омельченко // Техническое регулирование: базовая основа качества товаров и услуг. - Шахты: ЮРГУЭС, 2010. - С. 137-141.

\section{References}

1. Morekhodov, G. A. (1969). Ratsionalnoe ispolzovanie tekstinykh i iskustvenykh materialov pri raskroe na detail obuvi. Moscow: TSNIITYEIlegprom, 157.

2. Stoyan, Yu. G. (1970). Ob optimal'nom razmeschenii geometricheskikh obyektov. Moscow: 50
3. Stoyan, Yu. G. (1975). Razmeshcheniye geometricheskikh obyektov. K.: Naukova dumka, 175.

4. Maykl, Laslo (1997). Vychislitelnaya geometriya i kompyuternaya grafika na C++. M.:Izdatelstvo "BINOM", 340.

5. Vygodsky, M. Ya. (1956). Spravochnik po vysshey matematike. M., Hosudarstvenyi izdatelskiy dom tekhnicheskoy I teoreticheskoy literatury, 786 .

6. Zalgaller, V. A. (1953). Ob odnom neobkhodimom priznake plotneyschego raspolozheniya figur. Moscow:UMN, 4, 47.

7. Kantorovich, L. V., Zalgaller, V. A. (1951). Rastshet ratzionalnogo raskroya promyshlenych materialov. Spb.:Lenizdat, 128.

8. Mukhacheva, Ye. A. (1966). Ratsionalnyy raskroy pryamougolnykh listov na pryamoougolnye zagotovki. Novosibirsk, Optimal planning, 6, 39-41.

9. Tot, L. F. (1958). Raspolozhenie na ploskosti, v sfere i prostranstve. Moscow: Fizmattiz, 132.

10. Chuprinka, V. I., Murzhenko, V. S., Omelchenko, P. V. (2010). Algoritm postroyeniya opornoy funktsii dlya ploskikh geometricheskikh obyektov. Mezhdunarodnyy zbornik nauchnykh trudov "Technicheskoe regulirovanie: bazovye osnovy kachestva materialov, tovarov i uslug", Shachty: YuRGUES, 137-141.

Рекомендовано до публікації д-р техн. наук Тимошенко А. Г. Дата надходження рукопису 10.12.2014

Гаврилов Тарас Миколайович, аспірант, кафедра комп’ютерної інженерії, Відкритий Міжнародний Університет Розвитку Людини «Україна», вул. Львівська, 23, м. Київ, Україна, 03115

\author{
УДК 546.821-31:548.2
}

DOI: 10.15587/2313-8416.2015.35865

\title{
О ВОЗМОЖНОСТИ ПЕРЕКРИСТАЛЛИЗАЦИИ ДИСПЕРСНОГО РУТИЛА, РАСТВОРЕННОГО В РАСПЛАВЕ ГАЛОГЕНИДОВ ЩЕЛОЧНЫХ МЕТАЛЛОВ, В НИТЕВИДНЫЕ КРИСТАЛЛЫ
}

\author{
(C) В. П. Шапорев, А. В. Шестопалов, И. В. Питак
}

\begin{abstract}
В статье представлены теоретические и экспериментальные результаты практического получения нитевидных кристаллов путем перекристаллизачии дисперсного рутила, растворенного в расплаве галогенидов щелочных металлов. Рассчитанные кинетические параметры позволяют организовать процесс с заданной скоростью протекания и необходимым выходом продукта. Установлена возможность перекристаллизаиии оксида титана в солевом расплаве при продувке газом и газом с восстановителем в виде нитевидных кристаллов волокнистой формы
\end{abstract}

Ключевые слова: нитевидные кристаллы, оксид титана, кинетические параметры, кристаллизация, расплав солей

In the article the theoretical and experimental results of practical receipt of threadlike crystals are represented by recrystallization of dispersible rutile saluted in fusion of halide of alkaline metals. The expected kinetic parameters allow to organize a process with the set speed of flowing and necessary output of product. Possibility of recrystallization of titanium oxide is set in molten salt at blowing out by gas and gas with a repairer as the threadlike crystals with fibred form

Keywords: threadlike crystals, titanium oxide, kinetic parameters, crystallization, molten salt

\section{1. Введение}

Диоксид титана как белый пигмент широко применяется в промышленности, а также используется при изготовлении искусственных сапфиров и рубинов, для создания определенной структуры минералов в результате отложения игольчатых кристаллов рутила [1]. Игольчатые формы диоксида титана могут быть получены искусственно в результате окисления $\mathrm{K}_{2} \mathrm{TiCl}_{6}$ или псевдоаморфной перестройкой гексатитаната калия [2], а также путем окисления $\mathrm{TiCl}_{4}$ кислородом воздуха [3].
В большинстве случаев основная задача заключается в выращивании достаточно тонких длинных монокристаллов, обладающих свойствами волокна, а не в получении обычно образующих тетрагональных игл [4]. При этом предпочтительно, чтобы монокристаллы, обладающие свойствами волокна имели внутренние полые каналы (поры), что позволяет их использовать в качестве армирующих наполнителей [5], катализаторов, теплоизоляции и т. п. [6]. 


\section{2. Литературный обзор}

Согласно процессу, разработанному в [7-9] для производства волокнистого диоксида титана использование системы раствор-расплава $\mathrm{KCl}-\mathrm{NaCl}-\mathrm{TiCl}_{\mathrm{n}}$ при рациональных соотношениях основных компонентов: $\mathrm{KCl} / \mathrm{NaCl}=1 / 1, \sum \mathrm{TiCl}_{2}, \mathrm{TiCl}_{3}$ от $\sum \mathrm{KCl}, \mathrm{NaCl}-10 \%$ мacc., для $\mathrm{TiCl}_{3}$ от $\sum \mathrm{TiCl}_{2}, \mathrm{TiCl}_{3}-30-35 \%$ масс. Над расплавом продувается воздух со скоростью 15-40 мл/мин. на грамм $\left(\sum \mathrm{TiCl}_{2}, \mathrm{TiCl}_{3}\right)$. При этом температура реакционной смеси 1100-1200 К. При пропускании воздуха над расплавом с указанной скоростью по высоте слоя расплава возникает градиент температур $\Delta \mathrm{T} \leq 40^{\circ}$ и в приповерхностном слое $\mathrm{H}=3-6$ мм образуются волокна $\mathrm{TiO}_{2}$. Процесс образования $\mathrm{TiO}_{2}$ происходит в раствор-расплаве за счет окисления и диссоциации термически неустойчивой фазы $(\mathrm{MeCl})$ $\mathrm{TiCl}_{2}$. В растворе-расплаве образуется насыщенный раствор $\mathrm{TiO}_{2}$ и происходит кристаллизация его в виде волокон. Волокна $\mathrm{TiO}_{2}$ кристаллизуются в виде рутила и имеют поперечный размер в пределах 0,5-2,5 мкм, длинной до $10^{3}-10^{4}$ мкм, $1 / \mathrm{d}=4000-5000$.

Развитие исследований в соответствии с работами [7-9] показали [10], что изменяя покомпонентный состав продуваемого над расплавом газа и вводя в раствор-расплав примесные центры $\left(\mathrm{WCl}_{4}, \mathrm{Ta}_{2} \mathrm{O}_{5}, \mathrm{~V}_{2} \mathrm{O}_{5}\right.$, $\mathrm{Nb}_{2} \mathrm{O}_{5}, \mathrm{WO}_{3}$ и др.) можно изменять не только скорость роста волокон, но и вид геометрической фигуры кристалла в сечении от кольцевого до клиновидного, гангелеподобного и в виде дитригона, а также их размеры.

\section{3. Постановка проблемы}

Анализ вышеприведенного показал, что представляет практический и научный интерес исследовать возможность перекристаллизации $\mathrm{TiO}_{2}$, предварительно введенной расплавы $\mathrm{KCl}-\mathrm{NaCl}$ и $\mathrm{KCl}-\mathrm{NaCl}-$ $\sum \mathrm{TiCl}_{\mathrm{n}}$ в виде дисперсной фазы, в волокнистый оксид титана. Это диктуется тем, что согласно [7-10] при уже вышеописанных соотношениях компонентов солей расплава растворимость $\mathrm{TiO}_{2}$, вводимой в расплав для перекристаллизации, при $1000 \mathrm{~K}$ составляет соответственно $10 \%$ масс. от $\sum \mathrm{KCl}, \mathrm{NaCl}$ и $30 \%$ масс. от $\sum \mathrm{TiCl}_{2}$, $\mathrm{TiCl}_{3}$ при использовании системы $\mathrm{KCl}-\mathrm{NaCl}-\sum \mathrm{TiCl}_{2}$, $\mathrm{TiCl}_{3}$.

Если над расплавом для создания градиента температур продувать инертный газ, то есть газ, не содержащий $\mathrm{O}_{2}$, можно резко уменьшить или исключить образование $\mathrm{HCl}$ и $\mathrm{Cl}_{2}$, что позволит упростить процесс и повысить его безопасность, а комбинируя состав газовой фазы возможно получить новые формы волокнистой $\mathrm{TiO}_{2}$.

Исследований в указанном направлении кроме [7-10] нами не обнаружено. Поэтому в данной статье представлены результаты экспериментальных исследований по процессу перекристаллизации $\mathrm{TiO}_{2}$ в указанных выше системах расплавов.

\section{4. Методика проведения экспериментов}

При исследовании использовались следующие реагенты: $\mathrm{KCl}$ (калий хлористый), ЧДА ГОСТ4234-69; $\mathrm{NaCl}$ (натрий хлористый), ЧДА ГОСТ4233-47; плав субхлоридов титана в чистом $\mathrm{NaCl}$. Содержание субхлоридов $\sim 60 \%$ масс., соотношение $\mathrm{TiCl}_{2}: \mathrm{TiCl}_{3}=4: 1$. Плав является полупродуктом металлотермического рафинирования титана в солевом расплаве. В качестве диоксида титана использовали $\mathrm{TiO}_{2}$ квалификации ОСЧ 7-3 ТУ 6-09-01-640-84. Массовая доля основного компонента составляла 98,9-99,5 \% масс., массовая доля ионов $\mathrm{Fe} \leq 0,006$. Исследования проводили в герметичной муфельной печи, в которую помещалась кювета из прозрачного плавленого кварца размером $600 \times 400 \times 69$ мм; высота заполнения кюветы расплавом варьировалась в пределах от 3 до 50 мм. В пространстве муфеля и на поверхности плава фиксировалась температура платино-радиевыми термопарами, которая при проведении эксперимента поддерживалась с точностью \pm 5 градусов.

Шихта для приготовления раствор-расплава в первом варианте состояла: $\mathrm{KCl}+\mathrm{NaCl}$ в соотношении 1:1 плюс $\mathrm{TiO}_{2}$ в количестве $5 \%$ масс. от $\sum \mathrm{KCl}, \mathrm{NaCl}$; во-втором варианте $-\mathrm{KCl} / \mathrm{NaCl}=1 / 1 ; \sum \mathrm{TiCl}_{2}, \mathrm{TiCl}_{3}$ от $\sum \mathrm{KCl}, \mathrm{NaCl}-10 \%$ масс. плюс $\mathrm{TiO}_{2}$ в количестве $10 \%$ масс. от суммы солей.

Оба вида шихты используют безводные компоненты, гомогенизированы, помещаются в кювету, а затем муфель печи. В муфеле печи кювета и ее содержимое нагревались до 1200 К, после чего - плав выдерживался 3 часа до полного растворения $\mathrm{TiO}_{2}$ (на 98,5-99 \%), при этом температура в камере печи и на поверхности плава была одинакова. После выдержки над системой (в камере муфеля) создавалось разряжение 400 мм. рт, ст. (0,054 МПа), а затем продувался аргон (или чистый азот) или смесь аргона с водородом (восстановительная атмосфера). Расход газа варьировался в пределах от 15 до 135 мл на 1 г массы солей, составляющих шихту. Это позволило по высоте слоя расплава создавать градиент температур 5-20 градусов и обеспечивать кристаллизацию продукта в приповерхностном слое. Перед проведением основных экспериментов проведено несколько опытов в соответствии с вышеописанной последовательностью с шихтой не содержащей $\mathrm{TiO}_{2}$ с целью определения фазового состава солевых компонентов после нагревания и продувки газом.

Структуру образовавшейся фазы в процессе кристаллизации исследовали с помощью дифрактометра ДРОН - 2 в $\mathrm{Cu}_{\alpha}$-излучении при напряжении в трубке 36 кВ и силе тока 10 мА. Монохроматором служид графит, что обеспечивало хорошее разрешение линий на дифрактограммах. Полученные образцы подвергались термическому анализу на дериветографе МОМ1500 при скоростях нагрева 10 град/мин., навеска образца 447 мг, чувствительность 50 мг. Замеры кристаллов, образующейся фазы и определение их структурных особенностей осуществлялось на электронном микроскопе УЭМ-100, морфологию кристаллов исследовали с помощью сканирующего электронного микроскопа JSM-2 (Япония). Кристаллографические параметры образующихся фаз даются в соответствии с таблицами ASTM.

\section{5. Результаты экспериментальных исследова- ний и их обсуждение \\ Исследование расплава системы $\mathrm{KCl}-\mathrm{NaCl}-$} $\sum \mathrm{TiCl}_{2}, \mathrm{TiCl}_{3}$ без $\mathrm{TiO}_{2}$ при температуре 1000-1100 K в атмосфере сухого аргона показали, что в охлажденных пробах расплава наблюдается в основном две фазы: термически стойкая $\left[\mathrm{MeCl} \cdot \mathrm{TiCl}_{2}\right]$ до 1300-1400 К и 
диссоциирующая фаза при 1000-1100 К $\left[(\mathrm{MeCl})_{2} \cdot \mathrm{TiCl}_{3}\right]$. Термическая стойкость и скорость диссоциации фазы $\left[(\mathrm{MeCl})_{2} \cdot \mathrm{TiCl}_{3}\right]$ зависит от скорости продувания газа, толщины слоя плава и состава компонентов газа.

В табл. 1 приведены данные по термической устойчивости указанных соединений. Данные, приведен- ные в таблице, свидетельствуют, что в интервале температур 1000-1300 К наиболее устойчивой фазой является фаза типа $\left[\mathrm{MeCl} \cdot \mathrm{TiCl}_{2}\right]$. Фаза $\left[(\mathrm{MeCl})_{2} \cdot \mathrm{TiCl}_{3}\right]$, судя по фазовому составу охлажденного расплава диссоциирует на $\mathrm{TiCl}_{2}$ и $\mathrm{Ti}_{\mathrm{TB}}$.

Термическая устойчивость и скорость распада фаз в системах $\mathrm{KCl}-\mathrm{TiCl}_{\mathrm{n}}, \mathrm{NaCl}-\mathrm{TiCl}_{\mathrm{n}}$

\begin{tabular}{|c|c|c|c|c|c|}
\hline Система & $\begin{array}{l}\text { Соотношение } \\
\mathrm{MeCl} / \mathrm{TiCl}_{4}\end{array}$ & $\begin{array}{l}\text { Темпера- } \\
\text { тура, К }\end{array}$ & $\begin{array}{c}\text { Изменение кон- } \\
\text { центрации } \mathrm{TiCl}_{4} \text { за } \\
5 \text { часов, \% }\end{array}$ & $\begin{array}{l}\text { Скорость распада } \\
\text { соединения, г/час }\end{array}$ & $\begin{array}{c}\text { Соединения, обнару- } \\
\text { женные в холодном } \\
\text { плаве }\end{array}$ \\
\hline \multirow{4}{*}{$\mathrm{KCl}-\mathrm{TiCl}_{3}$} & \multirow{2}{*}{$6: 1$} & 1000 & 0,37 & 0,0015 & \multirow{4}{*}{$\begin{array}{c}\mathrm{KCl},(\mathrm{KCl})_{2} \cdot \mathrm{TiCl}_{3} \\
\mathrm{TiCl}_{2}, \mathrm{Ti}, \mathrm{TiCl}_{3}\end{array}$} \\
\hline & & 1200 & 75,0 & 2,142 & \\
\hline & \multirow{2}{*}{$10: 1$} & 1000 & 0,32 & 0,00576 & \\
\hline & & 1200 & 72,5 & 1,305 & \\
\hline \multirow{4}{*}{$\mathrm{KCl}-\mathrm{TiCl}_{2}$} & \multirow{2}{*}{$6: 1$} & 1000 & 0,1 & 0,00285 & \multirow{4}{*}{$\begin{array}{c}\mathrm{KCl}, \mathrm{KCl} \cdot \mathrm{TiCl}_{2} \\
\mathrm{Ti}, \mathrm{TiCl}_{2}\end{array}$} \\
\hline & & 1200 & 10,5 & 0,2998 & \\
\hline & \multirow{2}{*}{$10: 1$} & 1000 & 0,09 & 0,00167 & \\
\hline & & 1200 & 11,2 & 0,2016 & \\
\hline \multirow{4}{*}{$\mathrm{NaCl}-\mathrm{TiCl}_{3}$} & \multirow{2}{*}{$6: 1$} & 1000 & 1,2 & 0,0343 & \multirow{4}{*}{$\begin{array}{c}\mathrm{NaCl}, \mathrm{NaCl} \cdot \mathrm{TiCl}_{3}, \\
\mathrm{TiCl}_{2}, \mathrm{Ti}, \mathrm{TiCl}_{3}\end{array}$} \\
\hline & & 1200 & 89,7 & 2,55 & \\
\hline & \multirow{2}{*}{$10: 1$} & 1000 & 1,42 & 0,0256 & \\
\hline & & 1200 & 90,5 & 1,629 & \\
\hline \multirow{4}{*}{$\mathrm{NaCl}-\mathrm{TiCl}_{2}$} & \multirow{2}{*}{$6: 1$} & 1000 & 0,85 & 0,0243 & \multirow{4}{*}{$\begin{array}{c}\mathrm{NaCl}, \mathrm{NaCl} \cdot \mathrm{TiCl}_{2} \\
\mathrm{TiCl}_{2}, \mathrm{Ti}\end{array}$} \\
\hline & & 1200 & 7,1 & 0,2035 & \\
\hline & \multirow{2}{*}{$10: 1$} & 1000 & 0,59 & 0,0162 & \\
\hline & & 1200 & 10,2 & 0,1836 & \\
\hline
\end{tabular}

Оценивая возможные реакции процесса разложения $\left[(\mathrm{MeCl})_{2} \cdot \mathrm{TiCl}_{3}\right]$ по изменению изобарно-изотермического патенциала, было установлено, что самопроизвольно в расплаве могут протекать две реакции

$$
2 \mathrm{TiCl}_{3 \%}=\mathrm{TiCl}_{2 \text { ж }}+\mathrm{TiCl}_{4 \text { г }}
$$

при $\mathrm{T}=923 \mathrm{~K}, \Delta \mathrm{G}=-1$ ккал/моль; при $\mathrm{T}=1123 \mathrm{~K}$, $\Delta \mathrm{G}=-4$ ккал/моль; $\mathrm{T}=1273 \mathrm{~K}, \Delta \mathrm{G}=-7$ ккал/моль;

$$
2 \mathrm{TiCl}_{3 \text { ж }}+\mathrm{TiCl}_{2 \text { ж }}=\mathrm{Ti}_{\text {тв }}+2 \mathrm{TiCl}_{4}
$$

при $\mathrm{T}=923 \mathrm{~K}, \Delta \mathrm{G}=7$ ккал/моль; при $\mathrm{T}=1123 \mathrm{~K}$, $\Delta \mathrm{G}=-10$ ккал/моль; $\mathrm{T}=1273 \mathrm{~K}, \Delta \mathrm{G}=-15$ ккал/моль.

Процесс разложения $\left[(\mathrm{MeCl}) \cdot \mathrm{TiCl}_{2}\right]$ протекает по уравнению

$$
2 \mathrm{TiCl}_{2 \text { ж }}=\mathrm{Ti}_{\mathrm{тв}}+2 \mathrm{TiCl}_{4 \text { г }} .
$$

Таким образом, можно сделать заключение, что в интервале температур 1000-1300 K фаза $\left[(\mathrm{MeCl}) \cdot \mathrm{TiCl}_{2}\right]$ в расплаве обладает достаточно высокой термостойкостью. Полученные экспериментальные данные позволяют также сделать вывод, что распад $\mathrm{TiCl}_{2}$ и $\mathrm{TiCl}_{3}$ происходит в расплаве, а не в газовой фазе, так как в противном случае накапливание металлического титана в расплаве не влияло бы на скорость распада, да и значительная доля Ті осаждалась бы вне зоны расплава. В натуре же слой расплава на дне и стенках реактора был наиболее богат металлическим Ті. Следует отметить, что в расплавах, согласно уравнений процессов распада, находилось наибольшее количество $\mathrm{TiCl}_{4}$. Было установлено, что в присутствии $0,25 \%$ масс. $\mathrm{TiCl}_{4}$ и более, термостойкость соединений повышается, что связано с наличием небольших количеств $\mathrm{TiCl}_{4}$, вступающих с появляющимся металлическим титаном в обратную реакцию.
На рис. 1 приведены образцы металлического Ті обнаруженные на дне и стенках кюветы. Размеры микросфер находятся в интервале от 0,5-2,5 мкм, сами частицы представляют собой полые микросферы, состоящие из наночастиц $\mathrm{Ti}$, а на торце полости имеют, по видимому, выходы дислокаций.

В процессе перекристаллизации рутила $\left(\mathrm{TiO}_{2}\right)$, растворенного в расплаве галогенидов щелочных металлов с добавками калийсодержащих соединений (второй вариант шихты) в присутствии восстановителя $\left(\mathrm{H}_{2}\right)$ получены блестящие нитевидные кристаллы угольно-черного цвета. Диаметры кристаллов находятся в диапазоне 3-30 мкм, длина $-10^{3}-10^{4}$ мкм.

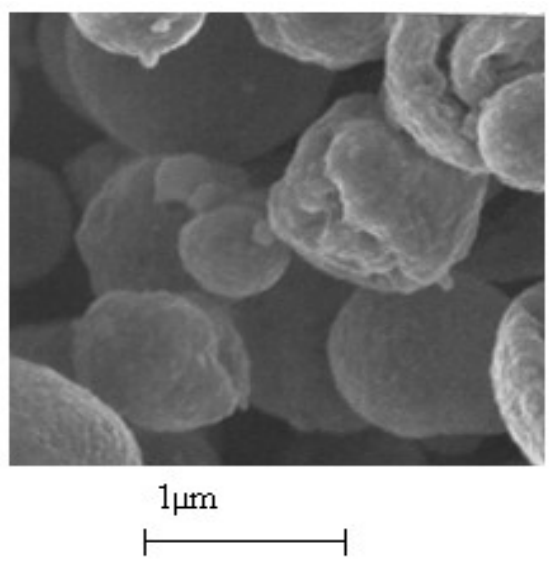

Рис. 1. Полые диформированные микросферы $\mathrm{Ti}_{\mathrm{тв}}$ на дне реактора, образующиеся по реакциям (1)-(2)

Выяснилось, что они имеют структуру прайдерита, австралийского минерала, изученного впервые 
Норришем [11] и затем искусственно им синтезированного. Дифрактограммы синтезированных нитевидных кристаллов и прайдерита приведены в табл. 2.

Таблица 2

Дифрактограммы прайдерита и синтезированных нитевидных кристаллов

\begin{tabular}{|c|c|c|c|}
\hline \multicolumn{2}{|c|}{ Прайдерит } & $\begin{array}{c}\text { Синтезированные ните- } \\
\text { видные кристаллы }\end{array}$ \\
\hline $\mathrm{I}, \%$ & $\alpha, \AA$ & $\mathrm{I}, \%$ & $\alpha, \AA$ \\
\hline 70 & 7,14 & 10 & 7,14 \\
\hline 70 & 5,05 & 100 & 5,07 \\
\hline 20 & 3,58 & 37 & 3,36 \\
\hline 100 & 3,20 & 11 & 3,24 \\
\hline 20 & 2,53 & 2 & 3,06 \\
\hline 80 & 2,47 & 37 & 2,53 \\
\hline 20 & 2,26 & 1,5 & 2,39 \\
\hline 20 & 1,98 & 6 & 2,28 \\
\hline 60 & 1,89 & 12 & 1,99 \\
\hline 10 & 1,79 & 2 & 1,895 \\
\hline 40 & 1,69 & 63 & 1,689 \\
\hline 50 & 1,58 & 4 & 1,598 \\
\hline 40 & 1,48 & 3 & 1,439 \\
\hline 10 & 1,42 & 30 & 1,39 \\
\hline 40 & 1,397 & & \\
\hline 20 & 1,33 & & \\
\hline 20 & 1,26 & & \\
\hline 20 & 1,158 & & \\
\hline 20 & 1,118 & & \\
\hline 40 & 1,03 & & \\
\hline 20 & 1,011 & & \\
\hline
\end{tabular}

*ASTM - международная картотека порошковых дифрактограмм.

В [11], а также исследования других авторов [12, 13] приведена приблезительная формула прайдерита, полученная на основе химического анализа $(\mathrm{K}, \mathrm{Ba})_{1,33}(\mathrm{Ti}, \mathrm{Fe})_{8} \mathrm{O}_{16}-y$ и общая формула $A_{2-\mathrm{y}}-B_{8-\mathrm{z}}-\mathrm{O}_{16}$, где $A$ - ионы $\mathrm{K}^{+}$и $\mathrm{Ba}^{2+}$ больших размеров, $B$ - меньшие по размеру ионы $\mathrm{Ti}^{4+}, \mathrm{Fe}^{3+}, y-$ имеет значение, мало отличное от единицы, $z$ - очень малое.

Одним из способов синтеза прайдерита является нагрев порошка $\mathrm{TiO}_{2}$ и $\mathrm{K}_{2} \mathrm{CO}_{3}$ в окислительном пламени [11]. Это указывает на возможность образования структуры прайдерита без участия бария, что совпадает с общей формулой, приведенной А.С. Поваренных [14], $\mathrm{K}_{2} \mathrm{Ti}_{2}{ }^{3+} \mathrm{Ti}_{6} \mathrm{O}_{16}$, который указывает на возможность замещения $\mathrm{K}^{+}$на $\mathrm{Ba}^{2+}$ в пределах $6,7 \%$.

Отсутствие в наших опытах в шихте Ва и $\mathrm{Fe}$, а также качественные химические анализы, не показавшие наличия этих элементов в полученных нами нитевидных кристаллах, позволили предположить изоморфное замещение ионов $\mathrm{Fe}^{3+}$ ионами $\mathrm{Ti}^{3+}$. Это предположение подтверждается близкими значениями ионных радиусов $\left(0,67 \AA\right.$ для $\mathrm{Fe}^{3+}$ и $0,69 \AA$ для $\left.\mathrm{Ti}^{3+}\right)$ [15]. На дериватограмме (рис. 2), заметно увеличение массы образца на 1,7 \% при нагревании до $860{ }^{\circ} \mathrm{C}(1132 \mathrm{~K})$, по-видимому, обусловленное окислением трехвалентного титана до четырехвалентного.

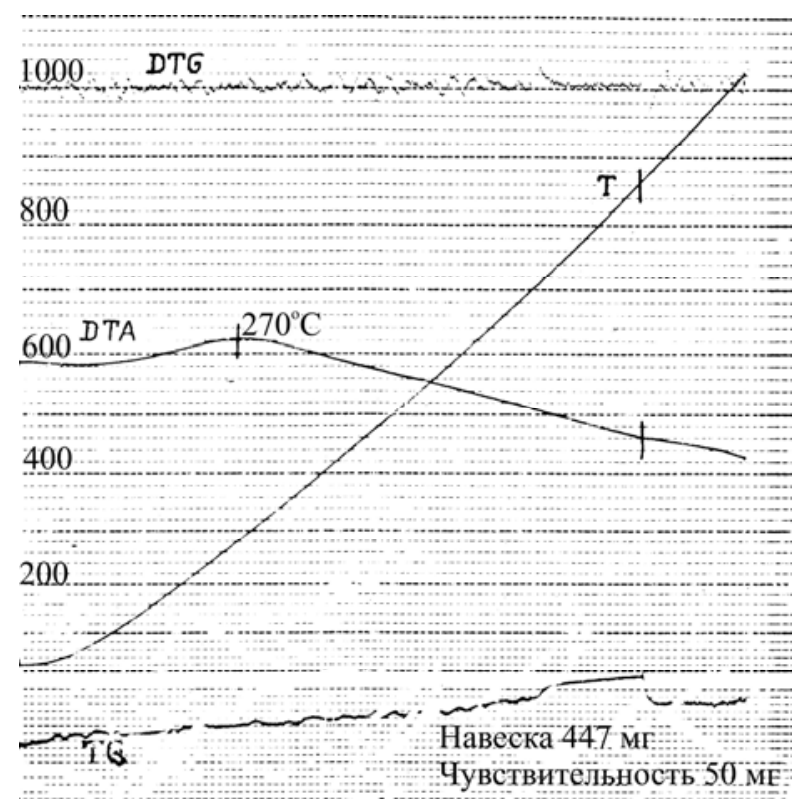

Рис. 2. Дериватограмма нитевидных кристаллов с прайдеритподобной структурой

Потеря массы при дальнейшем нагревании до $1000^{\circ} \mathrm{C}(1273 \mathrm{~K})$, вероятно, связана с улетучиванием $\mathrm{K}_{2} \mathrm{O}$. Рентгенографическое исследование образца, изменившего после прокаливания окраску на светложелтую показало, что он состоит из гексатитаната калия $\mathrm{K}_{2} \mathrm{Ti}_{6} \mathrm{O}_{13}$ с примесью рутила. Длительное прокаливание при $1000{ }^{\circ} \mathrm{C}$ приводит к превращению нитевидных кристаллов в рутил. Таким образом, приблизительная формула синтезированных нитевидных кристаллов имеет вид $\mathrm{K}_{2} \mathrm{Ti}_{2}{ }^{3+} \mathrm{Ti}_{6}{ }^{4+} \mathrm{O}_{16}$.

Морфологическое строение нитевидных кристаллов представлено на рис. 3-8.

Нитевидные кристаллы имеют форму тетрагональных призм, часто скелетных (рис. 3).

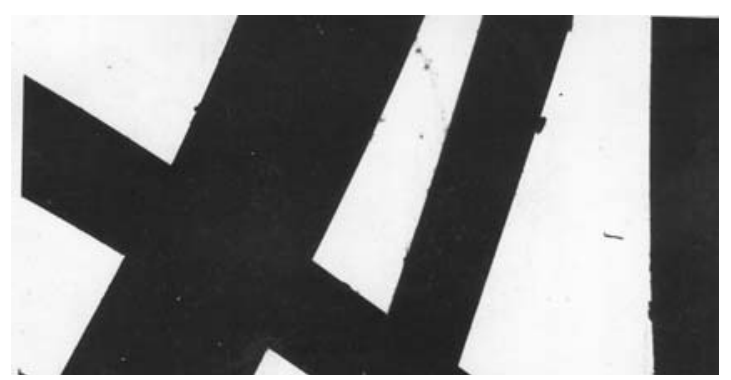

Рис. 3. Нитевидные кристаллы на основе диоксида титана с прайдеритподобной структурой (увеличение 400)

В некоторых усах наблюдали цилиндрические осевые полости, выходы которых на торцевые поверхности имеют ступени (рис. 4). Изображение на фотографии напоминает картину слоисто-спирального роста в местах выхода на поверхность кристалла винтовой дислокации. Радиус кристаллов в этом случае может быть вычислен по следующей формуле:

$$
r=\frac{b^{2} G}{8 H \sigma},
$$


где $b$ - вектор Бюргерса; $G$ - модуль сдвига; $\sigma$ - поверхностное натяжение.

Исходя из рис. 4 определим $\mathrm{r}=3$ мкм, и положив $\sigma=10^{3}$ эрг $/ \mathrm{cm}^{2}$ и $G=10^{12}$ дин $/ \mathrm{cm}^{2}$, можно оценить вектор Бюргерса. Полученное значения $b \approx 150 \AA$ можно объяснить наличием группы параллельных дислокаций одного знака, внесших вклад в образование канала.

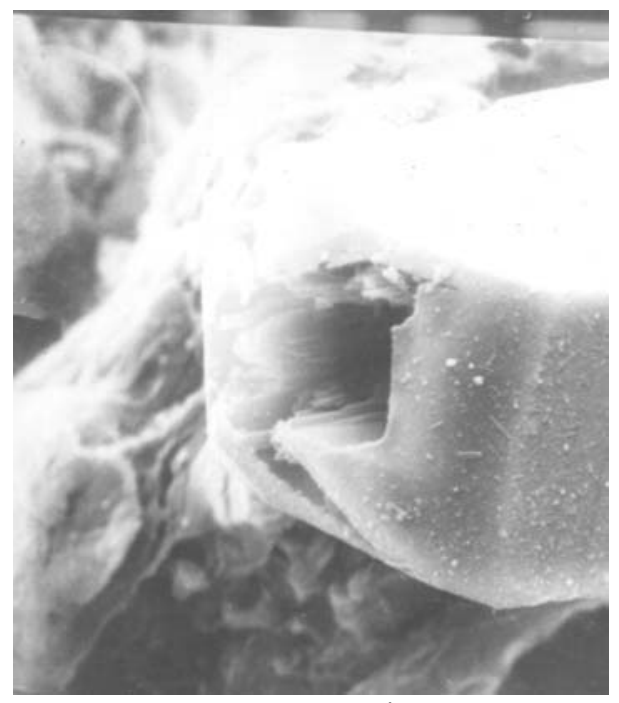

Рис. 4. Нитевидные кристаллы $\mathrm{TiO}_{2}$, имеющие цилиндрические осевые полости (увеличение 4000)

Кроме кристаллов, изображенных на рис. 4, наблюдали и нитевидные кристаллы с двумя цилиндрическими каналами (рис. 5).

Наряду с описанными дефектами в нитевидных кристаллах встречались коробчатые полости, занимающие большую часть объема, что указывает на их недислакационное происхождение (рис. 6). Этот вид кристаллов преобладал в объеме застывшего плава. Ориентировочно их количество составляло $\sim 80 \%$ от всей массы кристаллов.

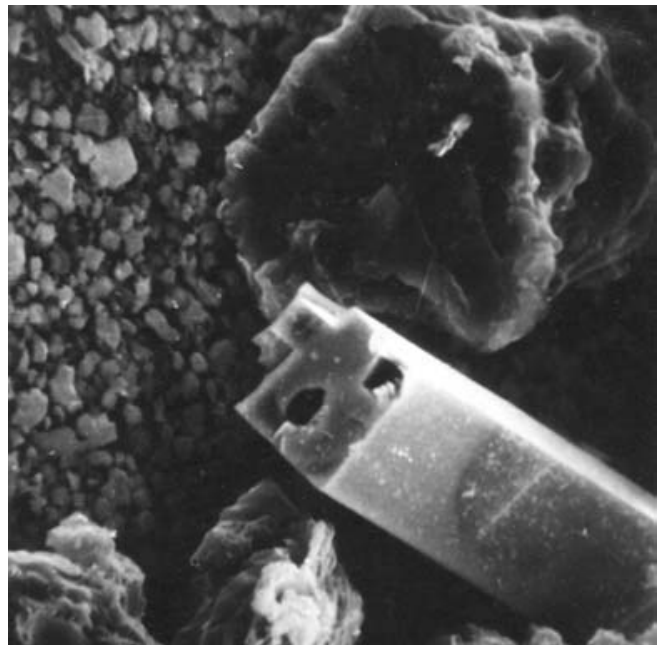

Рис. 5. Нитевидные кристаллы $\mathrm{TiO}_{2}$, имеющие две осевых цилиндрических полости

Некоторые нитевидные кристаллы, подобно изображенным на рис. 7, 8 наполнены волокнами, вросшими непосредственно в поре, проходящей через нитевидные кристаллы (рис. 7).
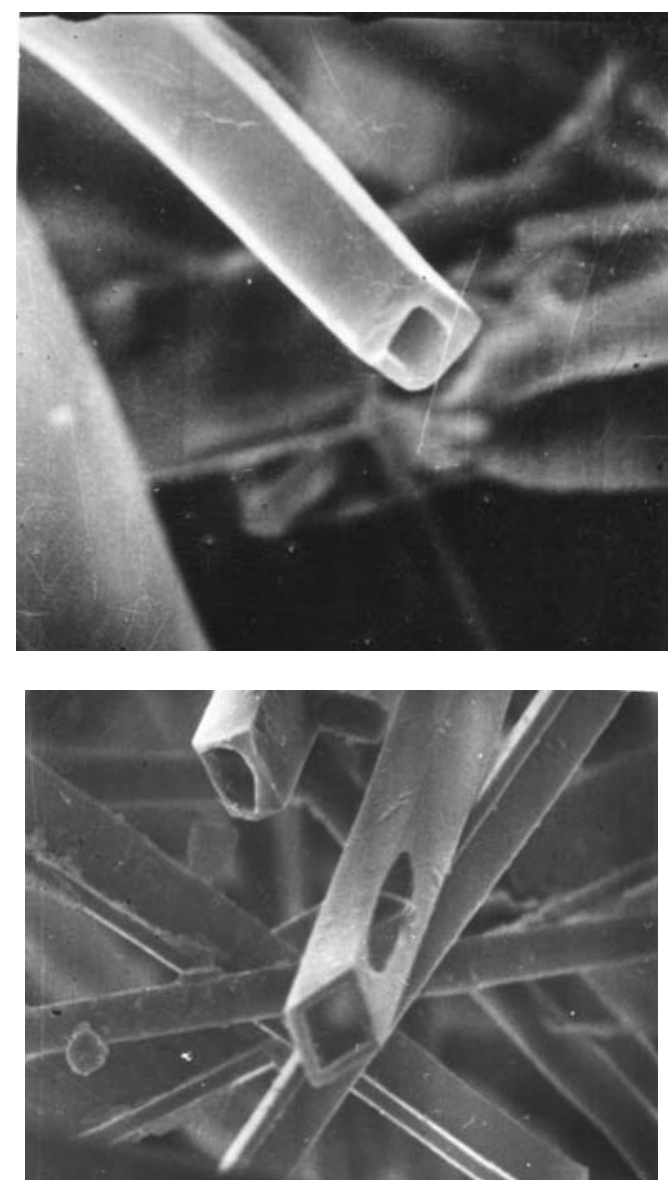

Рис. 6. Нитевидные кристаллы $\mathrm{TiO}_{2}$, имеющие коробчатые полости (увеличение 1500)

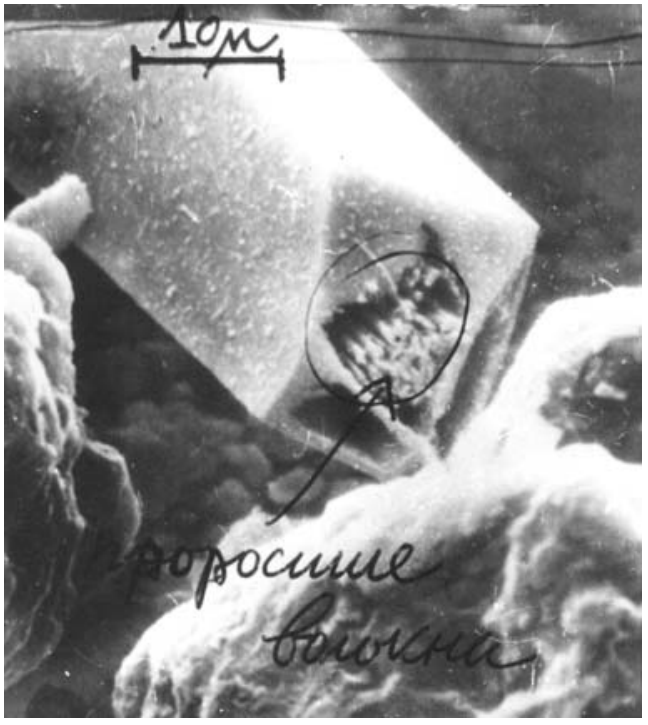

Рис. 7. Нитевидные кристаллы с волокнами, выросшими непосредственно в поре (увеличение 1500)

Диаметры нитей, как это видно на рис. 8, не превышают десятых долей микрона. Аналогичные наблюдения имели место в нитевидных кристаллах рутила, полученных из первого варианта шихты, в канале которых вырастали нитевидные кристаллы меньшего диаметра.

Однако, основная масса полученных кристаллов в последнем случае имела структуру типа коробчатой полости (рис. 9). 


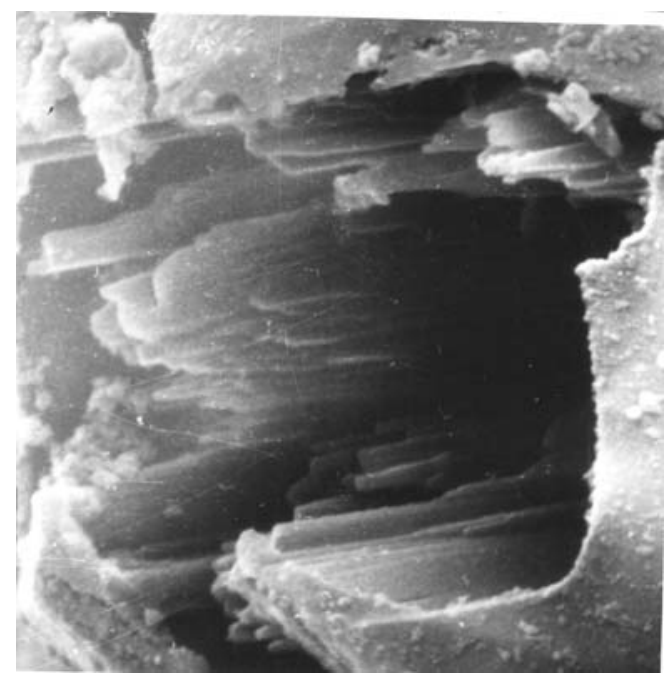

Рис. 8. Нитевидные кристаллы с волокнами, выросшими непосредственно в поре (увеличение 6500)

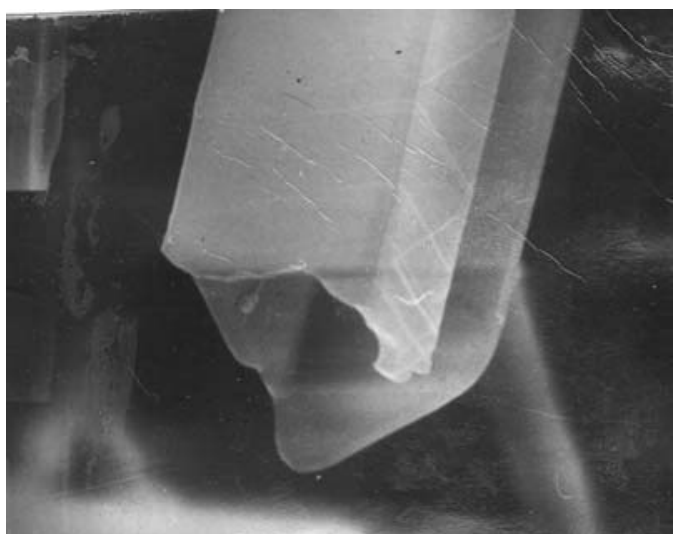

Рис. 9. Нитевидные кристаллы $\mathrm{TiO}_{2}$, имеющие коробчатые полости, полученные при исследовании шихты первого варианта (увеличение 1500)

Таким образом, полученные нитевидные кристаллы, по видимому, отвечают рекомендациям [4] и могут быть использованы для указанных в источнике целей.

\section{7. Выводы}

1. Установлена возможность процесса перекристаллизации оксида титана из раствор-расплавов $\mathrm{KCl}-$ $\mathrm{NaCl}$ и $\mathrm{KCl}-\mathrm{NaCl}-\sum \mathrm{TiCl}_{\mathrm{n}}$ в токе инертного газа и инертного газа, содержащего восстановитель, в виде нитевидных кристаллов волокнистой формы. Были получены нитевидные кристаллы рутила с поперечными размерами $30-30$ мкм и длиной $10^{3}-10^{4}$ мкм.

2. Исследована структура и морфология полученных кристаллических образований. Установлено, что в солевом расплаве $\mathrm{KCl}-\mathrm{NaCl}$ образуется нитевидные кристаллы $\mathrm{TiO}_{2}$ в виде тетрагональных призм, имеющие коробчатые полости, как при продувке инертным газом, так и при продувке инертным газом с восстановителем. В солевом расплаве $\mathrm{KCl}-\mathrm{NaCl}-$ $\sum \mathrm{TiCl}_{\mathrm{n}}$ при продувке газом с восстановителем нитевидные кристаллы приблизительно отвечают формуле $\mathrm{K}_{2} \mathrm{Ti}_{2}{ }^{3+} \mathrm{Ti}_{6}{ }^{4+} \mathrm{O}_{16}$ и имеют структуру прайдерита, основная масса кристаллов имеет коробчатые или цилиндрические полости. При продувке расплава $\mathrm{KCl}-\mathrm{NaCl}-$ $\sum \mathrm{TiCl}_{\mathrm{n}}$, не содержащего $\mathrm{TiO}_{2}$, инертным газом без восстановителя в объеме расплава кристаллизуется метал- лический титан в виде деформированных полых микpocфep.

\section{Литература.}

1. Siegel, R. W. Synthesis, Characterization, and Properties of Nanophase $\mathrm{TiO}_{2}$ [Text] / R. W. Siegel, S. Ramasamy, H. Hahn, Li Ting, Lu Zongquan, R. J. Gronsky // Journal of Materials Research. - 1988. - Vol. 3, Issue 6. - P. 1367-1372. doi: $10.1557 /$ jmr.1988.1367

2. Карролл-Порчинский, Ц. Материалы будущего. Термостойкие и жаропрочные волокна и волокнистые материалы [Текст] / Ц. Карролл-Порчинский; под. ред. Н. В. Михайлов. - М.: Химия, 1966. -237 с.

3. Suyama, $\mathrm{Y} . \mathrm{TiO}_{2}$ produced by vapor-phase oxygenolysis of $\mathrm{TiCl}_{4}$ [Text] / Y. Suyama, A. Kato // Journal of the American Ceramic Society. - 1976. - Vol. 59, Issue 3-4. - P. 146-149. doi: 10.1111/j.1151-2916.1976.tb09453.x

4. Третьяков, Ю. Д. Микро- и наномир современных материалов [Текст] / Ю. Д. Третьяков. - М: МГУ, 2006. - 69 с.

5. Weibel, A. Hot pressing of nanocrystalline $\mathrm{TiO}_{2}$ (anatase) ceramics with controlled microstructure [Text] / A. Weibel, R. Bouchet, R. Denoyel, P. Knauth // Journal of the European Ceramic Society. - 2007. - Vol. 27, Issue 7. - P. 2641-2646. doi: 10.1016/j.jeurceramsoc.2006.11.073

6. Knauth, P. Functionalized $\mathrm{TiO}_{2}$ nanoparticles for pigments, photoelectrochemistry, and solid state chemical sensors [Text] / P. Knauth, R. Bouchet, O. Scaf, A. Weibel, G. Auer; M.-I. Baraton (Ed.) // Synthesis, Functionalization and Surface Treatments of Nanoparticles. American Science Publications, Stevenson, 2002 (Chapter 8).

7. А. с. 1649851 СССР, МКИ С 30 В 9/12, 23/62, 29/22. Способ выращивания нитевидных кристаллов титанатов щелочных метал лов и тугоплавких окислов [Текст] / В. П. Шапорев, Л. А. Красникова, Г. А. Ткач (СССР). № 46186305/28; заявл. 13.12.88; зарег. 15.01.91, (для служебного пользования).

8. А. c. 1619756 СССР, МКИ ${ }^{5}$ С 30 В 29/62, 29/32, 9/00. Устройство для выращивания нитевидных кристаллов [Текст] / В. П. Шапорев, Л. А. Красникова, Г. А. Ткач (СССР). - № 4653751; заявл. 23.02.89; зарег. 08.09.90, (публикация запрещена).

9. Шапорев, В. П. Технологія неорганічних наповнювачів [Текст]: дис. ... д-ра техн.. Наук: 05.17.08 / В. П. Шапорев. - Харківський державний політехнічний інститут. Харків, 1995 - 365 с.

10. Шапорев, В. П. О возможностях применения методов нанохимии для анализа и интенсификации химикотехнологических процессов [Текст] / В. П. Шапорев, В. В. Себко // Вестник НТУ «ХПИ». - 2012. - № 61 (967). C. $164-176$.

11. Norrish, K. Priderite, a new mineral from the leucitelamproites of the west Kimherley area, Western Australia [Text] / K. Norrish // Mineralogical Magazine. - 1951. - Vol. 29, Issue 212. - P. 496-501. doi: 10.1180/minmag. 1951.029.212.03

12. Pring, A. Incommensurate superlattice ordering in priderite $[$ Text] / A. Pring, O. A. Jefferson // Mineralogical magazine. - 1983. - Vol. 47, Issue 342. - P. 65-68. doi: 10.1180/minmag.1983.047.342.11

13. Pryce, M. W. Griddle Jeppeite, a new K-Ba-Fe titanate from Walgidee Hills, Western Australia [Text] / M. W. Pryce, L. C. Hodge, A. J. Griddle // Mineralogical magazine. - 1984. Vol. 48, Issue 347. - P. 263-266.

doi: 10.1180/minmag.1984.048.347.11

14. Поваренных, А. С. Кристаллохимическая классификация минеральных видов [Текст] / А. С. Поваренных. Киев: Наукова Думка, 1966. - 547 с.

15. Бокий, Г. Б. Кристаллохимия [Текст] / Г. Б. Бокий. - М. Наука, 1971.— 400 с. 


\section{References}

1. Siegel, R. W., Ramasamy, S., Hahn, H., Zongquan, Li, Ting, Lu, Gronsky, R. (1988). Synthesis, Characterization, and Properties of Nanophase $\mathrm{TiO}_{2}$. Journal of Materials Research, 3 (6), 1367-1372. doi: 10.1557/jmr.1988.1367

2. Karroll-Porchinskiy, Ts. (1966). Materials of the future. Heat-resistant and heatproof fibers and fibred materials. Moscov, Khimiya, 237.

3. Suyama, Y., Kato, A. (1976). $\mathrm{TiO}_{2}$ produced by vaporphase oxygenolysis of $\mathrm{TiCl}_{4}$. Journal of the American Ceramic Society, 59 (3-4), 146-149.

doi: 10.1111/j.1151-2916.1976.tb09453.x

4. Tretyakov, Yu. D. (2006). Mykro- and nanoworld of modern materials Moscov, MGU, 69.

5. Weibel, A., Bouchet, R., Denoyel, R., Knauth, P. (2007). Hot pressing of nanocrystalline $\mathrm{TiO}_{2}$ (anatase) ceramics with controlled microstructure. Journal of the European Ceramic Society, 27 (7), 2641-2646.

doi: 10.1016/j.jeurceramsoc.2006.11.073

6. Knauth, P., Bouchet, R., Schaf, O., Weibel, A., Auer, G. (2002). Functionalized $\mathrm{TiO}_{2}$ nanoparticles for pigments, photoelectrochemistry, and solid state chemical sensors. Synthesis, Functionalization and Surface Treatments of Nanoparticles, ed. M.-I. Baraton. American Science Publications, Stevenson (Chapter 8).

7. Shaporev, V. P., Krasnikova, L. A., Tkach, G. A. (1991). Patent of USSR № 1649851. MKI C 30 B 9/12, 23/62, 29/22. The method of whiskering titian's of alkaline threw a catch and refractory oxides. Application number 46186305/28 1988.13.12, application date: January 15, 1991 (for the official use).

8. Shaporev, V. P., Krasnikova, L. A., Tkach, G. A. (1990). Patent of USSR № 1619756. MKI C 30 B 29/62, 29/32, 9/00. Device for the whiskering. Application number 4653751 1989.23.02, application date: September 8, 1990 (publication forbidden).

9. Shaporev, V. P. (1994). Technology of inorganic reinforcing fillers. Kharkov state polytechnic institute, Kharkiv, Ukraine, 365.

10. Shaporev, V. P., Sebko, V. V. (2012). About possibilities of application of methods of nano-chemistries for the analysis and intensification of chemical technological processes. Visnyk NTU «KhPI», 61 (967), 164-176.

11. Norrish, K. (1951). Priderite, a new mineral from the leucite-lamproites of the west Kimherley area, Western Australia. Mineralogical Magazine, 29 (212), 496-501. doi: 10.1180/minmag.1951.029.212.03

12. Pring, A., Jefferson, O. A. (1983). Incommensurate superlattice ordering in priderite. Mineralogical magazine, March 47, 65-68. doi: 10.1180/minmag.1983.047.342.11

13. Pryce, M. W., Hodge, L. C., Griddle, A. J. (1984). Griddle Jeppeite, a new K-Ba-Fe titanate from Walgidee Hills, Western Australia. Mineralogical magazine, 48 (347), 263-266. doi: 10.1180/minmag.1984.048.347.11

14. Povarennykh, A. S. (1966). Crystals chemistry classification of mineral prospects. Kiev, Naukova Dumka, 547.

15. Bokiy, G. B. Crystals chemistry. Moscow, Nauka, 400. Дата надходження рукопису 10.12.2014

Шапорев Валерий Павлович, доктор технических наук, профессор, кафедра химической техники и промышленной экологии. Национальный технический университет «Харьковский политехнический институт», ул. Фрунзе, 21, г. Харьков, Украина, 61002

E-mail: fiola2008@mail.ru

Шестопалов Алексей Валерьевич, кандидат технических наук, доцент кафедры химической техники и промышленной экологии, Национальный технический университет «Харьковский политехнический институт», ул. Фрунзе, 21, г. Харьков, Украина, 61002

E-mail: pheonix_alex@mail.ru

Питак Инна Вячеславовна, кандидат технических наук, доцент кафедры химической техники и промышленной экологии, Национальный технический университет «Харьковский политехнический институт», ул. Фрунзе, 21, г. Харьков, Украина, 61002

E-mail: ipitak5@gmail.com

УДК 656.212.2:004.353.24

DOI: 10.15587/2313-8416.2015.35869

\section{ВИКОРИСТАННЯ МЕТОДІВ АНАЛІЗУ ВІДЕОЗОБРАЖЕННЯ ДЛЯ КОНТРОЛЮ РОЗПУСКУ НА СОРТУВАЛЬНИХ ГІРКАХ. ЧАСТИНА 1}

\section{(C) І. М. Сіроклин, А. А. Бражник, В. О. Фоміна}

В роботі виконано огляд найбільш поширених методів аналізу відеозображення для виявлення руху на нерухомому фоні. Отримані результати проаналізовано з точки зору можливості контролю розпуску рухомого складу на сортувальних гірках. Для реалізації поставленої задачі застосовано метод віднімання фону. Для апробації результатів використано відеозаписи розпуску відчепів на сортувальній гіриі Одеса-сортувальна Ключові слова: аналіз відеозображення, виявлення руху відчепів, сортувальна гірка, контроль ділянок колї

A review of the most common video image analysis methods for detect motion in a stationary background is done in this article. The results are analyzed in terms of the ability to detaching control of rolling stock on hump yards. The background subtracting method is used for realization of this problem. The video of cuts detaching on OdesaSortuvalna hump yards are used for test the results

Keywords: video analysis, cuts motion detection, hump yard, track section control

\section{1. Вступ}

Дослідження, направлені на удосконалення мето- дів аналізу відеозображення, мають значну актуальність, оскільки потенційно можуть замінити велику 